\title{
La propiedad indígena como derecho humano y la explotación de sus recursos forestales en Costa Rica
}

\section{Federico Quesada Soto ${ }^{1}$ \& Elvis Cornejo Venegas ${ }^{2}$}

1. Licenciado en Derecho en la Universidad Autónoma de Centro América (2001). Máster en Derechos Humanos en la Universidad Estatal a Distancia de Costa Rica (2012). Procurador Penal. Procuraduría General de La República de Costa Rica. Intereses de investigación: derecho penal y derechos humanos. Costa Rica, Cartago. Tel.: 8323-3883. Correo electrónico: feder31@hotmail.com

2. Licenciado en Sociologia en la Universidad de Costa Rica. Master en Derechos Humanos en la Universidad Estatal a Distancia. Investigador, Educador. Administrador del Centro de Investigaciones Transferencia Tecnologica y Educacion para el Desarrollo CITTED UNED. Intereses de Investigacion: Desarrollo rural y gestión de recursos, derechos humanos, pueblos indígenas, campesinado y seguridad alimentaria, etnoconocimientos. Costa Rica, Alajuela, San Carlos. Tel.: 8714-6155. Correo Electronico: ecornejo@uned.ac.cr

\section{RESUMEN}

Las poblaciones indígenas han disfrutado de su tierra desde siglos, pero la intromisión del "hombre blanco" significó un cambio en su cosmovisión y en sus posibilidades de subsistencia acorde con su cultura, la cual es muestra de respeto hacia los recursos naturales. El derecho indígena es un derecho humano, pero los Estados se han caracterizado por plasmarlos más en el papel y menos en la práctica, esto ha conllevado a elevar el conocimiento de sus transgresiones hasta la Corte Interamericana de Derechos Humanos. Costa Rica, carece de reconocimiento constitucional expreso del derecho indígena y la legislación que regula la explotación de sus recursos forestales es insuficiente y plasmada de muestras de la hegemonía estatal sobre los derechos indígenas.

Palabras clave: Indígena, territorio, tierra, derechos humanos, recurso forestal.

\section{SUMMARY}

The aboriginal property as a human right and the exploitation of their forest resources in Costa Rica

The native populations have enjoyed the use of their lands per centuries, but the intromission of the "white man" meant a change of their worldview and their possibilities of subsistence according to their culture, which includes a significant respect towards to the natural resources. The aboriginal right is a human right, but the Estates tend to establish them more in paper than they do in the practice, so the transgressions to those rights has come to knowledge of the International Court of Human Rights. Costa Rica's constitutional law doesn't recognize the native right explicitly and the legislation that regulates the exploitation of their natural resources isn't sufficient and demonstrates the hegemony of the State over the aboriginal rights.

Key words: native, territory, land, human rights, forest resources.

\section{Introducción}

La propiedad indígena y en general, los derechos indígenas, han sido objeto de grandes y milenarias transgresiones, desconociéndose e irrespetándose a estos pueblos que han existido a lo largo de los siglos y que forman parte de nuestros antepasados. Pueblos y comunidades, que gozan de grandes riquezas culturales, tradiciones en desaparición y desaparecidas, y en su sentido puro, muestra y ejemplo de un encuentro armónico y espiritual con los recursos naturales.

En ese particular, la costumbre indígena en materia de tenencia de la tierra o territorios, implica la conservación de sus recursos naturales, mediante un uso equilibrado y respetuoso, en aras de transmitir ese legado a las futuras generaciones.

Con el transcurrir de los tiempos, los pueblos indígenas han sufrido de una grave disminución de sus territorios, protagonizada por los Estados que han asumido el control de esas tierras para dar paso a la explotación indiscriminada de los 
bosques hasta llegar a su desaparición, con la correlativa contaminación de aguas, sedimentación y afectación de los suelos, es decir, la destrucción de todo recurso natural que en él existieron y que constituyeron fuente de vida para estos pueblos.

Existe una generalidad, que tiende a reconocer, al menos en el papel, el derecho que los pueblos indígenas ostentan sobre sus territorios, entendiendo por esto, no solo la tierra en sí misma, sino todo lo que ella contiene, es decir el uso y disfrute de todos sus bienes, lo cual incluye los recursos naturales.

Sin embargo, la situación actual de nuestro mundo en grave descomposición, implica un reconocimiento, con límites, de los territorios indígenas; específicamente, en lo referente a la disposición y disfrute de los recursos naturales ubicados en sus terrenos, con especial énfasis para los efectos de este trabajo, del recurso forestal.

A pesar de la posibilidad de estos pueblos de gozar y disfrutar de los recursos naturales ubicados en sus tierras, el ejercicio de este derecho debe desarrollarse en armonía y respeto hacia los derechos también humanos de los que gozamos todos los habitantes de este planeta, como lo es, el medio ambiente.

El uso y explotación de la tierra y de sus diversos recursos, como el bosque, el agua y los animales, por ejemplo, constituyen un elemento esencial en el estilo de vida de los indígenas, sin embargo la intromisión de la actualidad en su cultura ha provocado desfases en el estilo y sentido de la vida indígena, a través de un proceso que Stavenhagen (1997), ha denominado como de aculturación.

Igualmente, el estado de enajenación y pobreza en el que se encuentran muchas comunidades y pueblos indígenas, los ha llevado a efectuar acciones de explotación de los recursos naturales contrarios a su cosmovisión, y que pueden significar la comisión de delitos ambientales.

\section{Desarrollo}

\section{Derechos humanos y derechos indígenas}

Los derechos indígenas ostentan la categoría de derechos humanos, y éstos pueden entenderse como un conglomerado de valores elementales que son inherentes al ser humano, cuyo reconocimiento social y jurídico emerge desde luchas sociales que han encontrado valor jurídico a través de su incorporación al derecho positivo, en la expresión de diversos instrumentos internacionales de derechos humanos, los cuales a su vez han formado parte de la normativa interna de gran cantidad de países que integran el Sistema Interamericano de Derechos Humanos.

A partir de la categoría de derechos humanos, podemos indicar que éstos poseen una serie de características definidas a nivel doctrinario (De Castro-Cid, 2003); son universales, toda vez que constituyen derechos para todos y todas las personas del mundo, son inalienables, en virtud de que su dominio es intransmisible e indisponible, son irrenunciables e imprescriptibles, por cuanto, en principio, no es factible su prescindir de ellos y su ejercicio y garantía no fenece con el transcurso del tiempo.

Estas, son características generales que pueden cuestionarse y tener variantes, así en el supuesto del derecho indígena a sus territorios, es claro que carece de la característica de universalidad al entender que se trata de un derecho que goza de la particularidad de estar circunscrito a ciertos grupos de personas que gozan de una cultura específica de gran riqueza, pero que lamentablemente ha sido objeto de abusos, intervenciones e injerencias que la han colocado en una situación de grave vulnerabilidad.

En todo caso, el reconocimiento, respeto y efectividad en la aplicación de los derechos indígenas, constituye una condición inequívoca en la configuración de su dignidad humana, toda vez que ello deviene imperativo para el mantenimiento de su identidad cultural.

A pesar de haber alcanzado la categoría de derechos humanos reconocidos en diversos instrumentos internacionales, sus territorios y sus riquezas han estado al alcance de los intereses económicos de diversos grupos; madederos, agropecuarios y de explotación minera e hidrológica, lo que ha requerido la intervención de órganos jurisdiccionales de carácter internacional, como lo es la Corte Interamericana de Derecho Humanos, en protección de sus derechos. 
Desde el enfoque de los derechos humanos, es factible afirmar que los derechos indígenas son inherentes a su naturaleza humana, por lo que existen y son exigibles con independencia de su reconocimiento jurídico-político, además, su respeto y positivización es sin lugar a dudas criterio de legitimidad y límite de los grupos de poder que gobiernan los Estados.

Siguiendo a De Castro Cid (2003, p.133) podemos indicar que se trata de un derecho natural al constituir "facultades del sujeto asentadas no en la norma positiva sino en un ordenamiento superior que es lo que les presta su universalidad e intangibilidad frente al poder,...natural en cuanto distinto del positivo $\mathrm{y}$, a su vez, preliminar y fundamental respecto a éste". A pesar de ello, consideramos evidentemente necesario contener sus derechos en normas positivas con el objeto de lograr su eficacia, o al menos poder exigirla.

\section{La propiedad indígena}

El derecho a la propiedad privada, había sido entendido históricamente como un derecho de carácter individual, prácticamente sagrado e intocable, de uso ilimitado y sin restricciones, sin embargo actualmente la propiedad privada ha sufrido de una variación de trato y es factible imponerle limitaciones al derecho de uso y explotación.

Toda persona, tiene derecho a que se respete su propiedad privada salvo excepciones por motivos de utilidad pública legalmente declarados, conforme lo dispone el artículo 45 de nuestra Constitución Política, en cuyos casos procedía y procede la aplicación del régimen de la expropiación.

Sobre el punto, dentro de la normativa internacional de los derechos humanos, la Declaración Americana de los Derechos y Deberes del Hombre de 1948, en el Artículo XXIII, establece, que "Toda persona tiene derecho a la propiedad privada correspondiente a las necesidades esenciales de una vida decorosa, que contribuya a mantener la dignidad de la persona y del hogar".

Antes de la concientización global acerca de la importancia del ambiente, que dio mérito a los derechos humanos de la solidaridad, la propiedad privada había sido entendida bajo una visión de explotación desmesurada que ha implicado la destrucción absoluta de enormes cantidades de bosques, contaminación de fuentes de agua, extinción de especies animales y vegetales, y pérdida de nuestro hábitat natural.

Con ocasión de esta concepción de la tierra y el desarrollo de un sistema de producción de salvaje capitalismo, todos los países donde existe o existió población indígena, la han desplazado de los territorios que milenariamente habían ocupado, para dar paso a la ocupación de intereses económicos particulares y estatales, sin que hayan importado las consecuencias funestas que esto ha tenido o pueda tener en el mantenimiento de la cultura, tradiciones y el entendimiento espiritual y sagrado que culturalmente relacionan a las poblaciones indígenas con la tenencia y utilización de sus tierras.

En nuestro país, un ejemplo de ello, es el Proyecto Hidroeléctrico Diquís, en la zona sur, el cual se ha convertido en un referente de unificación étnica y lucha cultural por un lado, y de ruptura enajenante por otro. Así, lo expone Amador (2003) en ponencia expuesta en el II Congreso sobre Pueblos Indígenas al indicar que "Los que sustentan la línea del pensamiento étnico, perciben la represa como una amenaza para la continuidad étnica. Los que sustentan la línea de ruptura, miran el proyecto como una opción de desarrollo que debe ser aprovechada por la comunidad".

En evidente contradicción al entendimiento de la propiedad inmueble por parte del llamado hombre blanco, la cosmovisión indígena marca una diferencia esencial entre los conceptos de tierra y territorio, ya que aunque los no indígenas podríamos asimilar ambos conceptos como sinónimos, acorde con Ferreto (1985), el primero nos ubica más en la cosmovisión indígena como la fuente de vida y de todo lo creado, por cuanto nace de una mujer y es mujer Iriria, la niña madre de la tierra y de todo aquello que nace de la tierra.

Por su parte, el territorio representa el espacio donde se desarrollan las personas, donde interactúan, comparten sus vidas, sus creencias, 
valores y costumbres. Es en este territorio, donde se delimitan las relaciones sociales, políticas y económicas de los pueblos indígenas, y donde adquieren sentido los derechos humanos y en particular toda la legislación nacional e internacional vigente en la actualidad. En sus territorios, se basa su interrelación entre la sociedad y la naturaleza, donde sus clanes (ditsewö) se designan con nombres de animales y plantas, donde el uso y manejo de los recursos naturales debe ser armonioso por ser fuente de vida y por lo tanto de respeto, donde los valles se utilizan para la agricultura y los bosques para la cacería.

Los territorios indígenas, constituyen la esencia de su ser, son expresión y fundamento de su cosmovisión, de su identidad, permiten la reproducción de etnoconocimientos y sabiduría, de alimentos y son la manera de conservar su patrimonio ancestral, cultural, físico, y el intangible patrimonio espiritual de sus grupos y pueblos; son su vida misma.

\section{Normativa internacional sobre la propiedad indígena y la explotación de sus recursos naturales}

Dentro del esquema internacional, encontramos el Convenio 169 sobre los Pueblos Indígenas y Tribales en pueblos independientes, emanado de la Organización Internacional del Trabajo, en Conferencia General de la Organización Internacional del Trabajo, convocada en Ginebra por el Consejo de Administración de la Oficina Internacional del Trabajo y congregada en dicha ciudad el 7 de junio de 1989.

Este convenio, está inspirado acorde con su exposición de motivos, en procurar que los pueblos indígenas y tribales asuman el control de, "sus propias instituciones y formas de vida y de su desarrollo económico y a mantener y fortalecer sus identidades, lenguas y religiones, dentro del marco de los Estados en que viven", y asimismo, para que puedan disfrutar de los derechos fundamentales, "en el mismo grado que el resto de la población de los Estados en que viven", tomando en cuenta, "que sus leyes, valores, costumbres y perspectivas han sufrido a menudo una erosión".
En relación con el tema de la explotación del recurso forestal en las propiedades indígenas, existen varios artículos del citado convenio que resultan de interés. De ellos, se deprende que al hablarse de tierras debe incluirse el concepto de territorio, lo cual abarca todo el hábitat de la región específica, ergo, incluye los recursos forestales. Sobre el punto, el numeral 13.2, establece que "La utilización del término "tierras" en los artículos 15 y 16 deberá incluir el concepto de territorios, lo que cubre la totalidad del hábitat de las regiones que los pueblos interesados ocupan o utilizan de alguna otra manera".

Asimismo, el artículo 15.1 del convenio de cita establece el reconocimiento del derecho indígena sobre los recursos naturales ubicados en sus territorios, al regular que "Los derechos de los pueblos interesados en los recursos naturales existentes en sus tierras deberán protegerse especialmente. Estos derechos comprenden el derecho de esos pueblos a participar en la utilización, administración y conservación de dichos recursos".

El convenio en referencia, está inspirado en lo concerniente al tema ambiental indígena, bajo la ideología de una relación simbiótica entre estos pueblos y el manejo y disfrute de los recursos naturales, esto consta en su exposición de motivos, al indicar que "Recordando la particular contribución de los pueblos indígenas y tribales a la diversidad cultural, a la armonía social y ecológica de la humanidad y a la cooperación y comprensión internacionales", lo que permite ir centrando el fundamento de una explotación y uso de los recursos naturales de los territorios indígenas y por indígenas, bajo la idea de una relación armoniosa y ambientalmente amistosa y aceptable.

Por su parte, la Declaración de las Naciones Unidas sobre los derechos de los pueblos indígenas del 2007, al tratar el tema de la tierra y sus recursos reconoce el derecho a las tierras, territorios y recursos que los indígenas tradicionalmente han poseído, ocupado y utilizado, exigiendo a los Estados su protección jurídica. En similar sentido, el ordinal 32 de la Declaración de mérito regula el derecho de los pueblos indígenas a determinar y confeccionar sus prioridades 
y estrategias en relación con el desarrollo y utilización de sus tierras y de sus recursos.

Acorde con esta normativa internacional, la explotación de los recursos naturales y por ende del recurso forestal, lo es, para promover, desarrollar y mantener sus costumbres, espiritualidad, tradiciones, procedimiento y prácticas, siempre y cuando estén adecuados con las normas internacionales que regulan los derechos humanos. Así lo dispone su numeral 34 al referir que "Los pueblos indígenas tienen derecho a promover, desarrollar y mantener sus estructuras institucionales y sus propias costumbres".

El tema del derecho de explotación de los recursos naturales por indígenas y dentro de sus territorios, debe entenderse en el marco de una interpretación evolutiva de las normas jurídicas, mediante la integración de normas internacionales, de modo que se reconozca el derecho en sí mismo y respecto de sus límites, entendido y aplicado en el actual contexto histórico.

Este principio de interpretación evolutiva, ha sido rescatado de la Corte Interamericana de Derechos Humanos, la cual en sentencia del 17 de junio del 2005b al resolver sobre el caso de la Comunidad Indígena Yakye Axa contra Paraguay, manifestó que;

la evolución de los tiempos y las condiciones de vida actuales ..., Tal interpretación evolutiva es consecuente con las reglas generales de interpretación consagradas en el artículo 29 de la Convención Americana, así como las establecidas por la Convención de Viena sobre el Derecho de los Tratado.

El derecho al territorio indígena, debe enmarcarse bajo un contexto de efectividad, que implica, su adjudicación, delimitación territorial y por supuesto, la posibilidad de uso y explotación de recursos, en relación con el derecho a la libre determinación y posibilidad de desarrollo económico, social y cultural de estos pueblos, pero sin que ello puedan significar una afectación a los derechos del resto de la colectividad.
La propiedad indígena: tratamiento jurisprudencial de la Corte Interamericana de Derechos Humanos

La Corte Interamericana de Derecho Humanos, ha sido enfática en referirse a la necesidad de los Estados en reconocer los derechos indígenas en igualdad de condiciones respecto del resto de la población, pero interpretando y aplicando tanto la normativa internacional, como la interna, tomando "en consideración las características propias que diferencian a los miembros de los pueblos indígenas de la población en general y que conforman su identidad cultural".; así lo dijo en sentencia del 17 de junio del 2005 al resolver el caso de la Comunidad Indígena Yakye Axa VS. Paraguay.

Asimismo, la Corte a través de la citada sentencia dictada contra Paraguay, ha reconocido la propiedad indígena dentro del texto del artículo 21 de la Convención Americana sobre Derechos Humanos, realizando una interpretación integral con el Convenio 169 de la OIT.

En ese particular, al conocer del caso de la comunidad indígena Sawhoyamaxa contra Paraguay, la Corte Interamericana valoró a la propiedad indígena desde su concepción colectiva, reconociendo las particularidades de su etnia, otorgando su respeto desde la diferencia e ignorando la concepción de trato homogéneo, es decir reconociendo su ciudadanía indígena y su especial vinculación con sus territorios. Así, mediante sentencia del 29 de marzo del 2006, la Corte indicó:

120. Asimismo, este Tribunal considera que los conceptos de propiedad y posesión en las comunidades indígenas pueden tener una significación colectiva, en el sentido de que la pertenencia de ésta "no se centra en un individuo sino en el grupo y su comunidad". Esta noción del dominio y de la posesión sobre las tierras no necesariamente corresponde a la concepción clásica de propiedad, pero merecen igual protección del artículo 21 de la Convención 
Americana. Desconocer las versiones especificas del derecho al uso y goce de los bienes, dadas por la cultura, usos, costumbres y creencias de cada pueblo, equivaldría a sostener que sólo existe una forma de usar y disponer de los bienes, lo que a su vez significaría hacer ilusoria la protección del artículo 21 de la Convención para millones de personas. 121. En consecuencia, la estrecha vinculación de los pueblos indígenas con sus tierras tradicionales y los recursos naturales ligados a su cultura que ahí se encuentren, así como los elementos incorporales que se desprendan de ellos, deben ser salvaguardados por el artículo 21 de la Convención Americana.

Como ya fue adelantado, la propiedad indígena es radicalmente diferente a la concepción clásica de la propiedad privada, se trata de una propiedad comunal, con unidad territorial, sus territorios no constituyen una simple cuestión de posesión y producción, sino que forma parte integrante y esencial del estilo de vida de sus pueblos y que son necesarios para el desarrollo y mantenimiento de su cultura, tradiciones y supervivencia.

El derecho al territorio indígena, implica la posibilidad real de efectuar una labor de explotación de la tierra y sus recursos a fin de permitir a estas poblaciones un desarrollo de vida acorde con su cultura y cosmovisión, de manera que logren subsistir mediante el uso y disfrute de los recursos naturales que existen en sus territorios.

Ahora bien, desde el trato jurisprudencial de la Corte se ha insistido en que el derecho al uso y goce de los territorios indígenas carecerían de sentido si no estuviera conectado con los recursos naturales ubicados en sus tierras, pero se marca un punto de importancia para generar supuestos en los cuales podrían establecerse limitaciones legales respecto de aquel aprovechamiento.

En este particular, al conocer el caso del Pueblo Saramaka contra Surinam, mediante sentencia del 28 de noviembre de 2007, la Corte expresó;

De este análisis, se entiende que los recursos naturales que se encuentran en los territorios de los pueblos indígenas y tribales que están protegidos en los términos del artículo 21 son aquellos recursos naturales que han usado tradicionalmente y que son necesarios para la propia supervivencia, desarrollo y continuidad del estilo de vida de dicho pueblo.

Ello tiene sentido, si se entiende que una eventual ejecución de acciones indígenas dirigidas a la explotación de los recursos naturales y específicamente del recurso forestal, bajo criterios alejados de sus tradiciones, cultura y cosmovisión y dirigidos a la generación de afectaciones al medio ambiente como podría ser el caso de la destrucción de los bosques, quedaría por fuera de la protección especial indígena y permitiría la legítima intromisión de las autoridades del Estado en aras de ejecutar la leyes ambientales, sentar responsabilidades y detener aquellas acciones que no estarían amparadas por la forma de vida indígenas.

Con este ejemplo, aun y cuando la ciudadanía indígena es una forma ampliada de la ciudadanía común, ésta no se encuentra excluida del cumplimiento de las obligaciones ambientales que tenemos todas las personas como una forma de respeto por el derecho humano al medio ambiente, siempre y cuando obligaciones derivadas del llamado hombre blanco no signifiquen una denegación de las tradiciones y costumbres indígenas de forma tal que coloque en una situación de peligro la subsistencia de la comunidad respectiva.

Bajo la exposición hecha de los lineamientos establecidos por la Corte Interamericana de Derechos Humanos, es posible afirmar que pueden establecerse limitaciones a la propiedad indígena en relación con la explotación de los recursos forestales ubicados en bosques y áreas de protección, según defina la ley.

La explotación de los recursos forestales, por indígenas, en territorios indígenas de Costa Rica

El reconocimiento de los derechos humanos dentro de la estructura de protección jurídica de los países, ha dado pie a la doctrina (Doménech, 2006) de los derechos fundamentales a protección. Se trata, de derechos con reconocimiento 
constitucional, desarrollo legal y que gozan de tutela judicial, existiendo obligaciones estatales de protección que implican acciones positivas y negativas, entendidas como derechos prestaciones y derechos defensivos, lo cual incluye el derecho de la propiedad indígena y el derecho al medio ambiente.

En el caso de Costa Rica, el derecho al territorio indígena carece de fundamento expreso constitucional, aunque podría interpretarse que desde el derecho a la propiedad privada puede derivarse mediante una interpretación evolutiva e integral, el derecho a la propiedad indígena.

Asimismo, a pesar de que la Corte Interamericana $^{1}$ ha resaltado en innumerable cantidad de ocasiones la obligación de los Estados de organizar el aparato gubernamental y sus estructuras de forma tal que se asegure el cumplimiento del libre y pleno ejercicio de los derechos humanos, para el caso de la materia indígena la estructura existente en relación con la organización, protección, delimitación y manejo de sus territorios, es lamentable e insuficiente.

Aclarado esto, sí existe normativa legal que se ha ocupado de abordar el tema de los territorios indígenas y de la explotación del recurso forestal dentro de éstos. Además del Convenio 169 de la OIT que es Ley 7316 del 3 de noviembre de 1992, existe la Ley Indígena número 6172 del 29 de noviembre de 1977, la cual en su artículo tercero declara a las reservas indígenas (no habla de territorios), inalienables, imprescriptibles, no transferibles y exclusivas para los indígenas que las habitan.

Acerca de los recursos forestales, en los numerales 6 y 7 de la ley se establece lo propio para su explotación. Así, se indica que solamente los indígenas están facultados para talar árboles y explotar los recursos maderables ubicados dentro de los límites de las reservas, lo cual debe

1. Caso Godínez Cruz Vs. Honduras, Sentencia de 20 de enero de 1989. En igual sentido, Caso Cabrera García y Montiel Flores vs, México, sentencia de 26 de noviembre de 2010, Caso Albán Cornejo y otros vs Ecuador, sentencia de 22 de noviembre del 2007, Caso Herrera Ulloa vs Costa Rica, sentencia de 2 de julio del 2004. hacerse de manera racional, y marca la obligatoriedad de mantener los terrenos con vocación forestal, sea mantener los bosques, a efecto de evitar la alteración del equilibrio hidrológico de las cuencas hidrográficas así como para conservar la vida silvestre de aquellas regiones.

Elaborando un análisis integral de los derechos indígenas, sus territorios y la regulación legal nacional para la explotación del recurso forestal, consideramos factible afirmar que los indígenas están en plena capacidad de hacer uso y explotación del recurso forestal situado en sus territorios, siempre y cuando se adecuen a su tradicional forma de vida, en aras de continuar con sus costumbres y con sus métodos de subsistencia.

A pesar de que la normativa nacional, específicamente la Ley Forestal, permite la explotación de bosques únicamente a través de su ejecución mediante planes de manejo, en el caso indígena la eventual tala y aprovechamiento de árboles en bosques podrá realizarse sin necesidad de este requerimiento legal, con la única obligación indígena de ejercer aquella explotación acorde con sus forma de vida, subsistencia y para la conservación de sus costumbres, haciéndolo de manera racional y sin que aquellas actividades impliquen la destrucción de la estructura conformadora de los bosques.

A su vez, y si se quiere de manera contradictoria con el respeto de los derechos indígenas, la misma Ley Indígena establece lo que constituye una clara imposición de hegemonía sobre los territorios indígenas y sobre sus recursos forestales, al establecer que el Estado podrá realizar programas forestales en bosques, bajo la autorización y vigilancia del CONAI.

Nótese, como la ley misma ignora los procesos de consulta previstos en el Convenio 169, que exige el diálogo con la específica población indígena donde pueda pretenderse desarrollar un programa forestal por parte del Estado, y procura sustituir la consulta mediante la autorización de una institución que se encuentra inspirada en las teorías integracionistas que buscaban la asimilación de los pueblos indígenas al resto de la sociedad, como lo muestra su artículo cuarto al expresar que son objetivos fundamentales de la 
CONAI, integrar las comunidades aborígenes al proceso de desarrollo.

En este punto, es evidente que la CONAI de ninguna manera representa a las poblaciones indígenas, conforme lo expuso la Sala Constitucional mediante voto 6856-2005, de modo que plantear esta posibilidad de explotación forestal significa desconocer los derechos de los pueblos indígenas, a la luz del Convenio de la 169, de la Declaración de la ONU y de la misma jurisprudencia de la Corte Interamericana de Derechos Humanos. Y es que, cómo podría esta Comisión Nacional de Asuntos Indígenas con su estructura, intereses y objetivos, representar seriamente a los ocho grupos indígenas distintos que existen en el país, a saber, Bribris, Cabécares, Ngäbe, Térrabas, Borucas, Huetares, Malecus y Chorotegas, los cuales habitan en 24 territorios y hablan en 6 idiomas indígenas.

Dentro de la normativa nacional, existe el Reglamento para el Aprovechamiento del Recurso Forestal en las Reservas Indígenas de 1999, a través del cual, el Estado regula la explotación de los bosques y del recurso maderable en las denominadas reservas. Desde esta reglamentación, se permite el aprovechamiento del recurso forestal dentro de los territorios indígenas (reservas según la nomenclatura utilizada) en terrenos sin bosques y cuando se persigan fines domésticos para beneficio de sus habitantes e indica que la explotación deberá ser autorizada por las Asociaciones de Desarrollo Indígena.

Asimismo, se limita el permiso por año, siendo posible aprovechar de tres y hasta diez árboles por hectárea. Luego de la solicitud, la asociación indígena, previa inspección de un guarda forestal indígena, determina a ese nivel si procede o no el aprovechamiento y posteriormente canalizan la solicitud con su previa aprobación, ante el Minaet quien finalmente define o no la tala.

Esta maraña burocrática, constituye otro ejemplo de la función de control del Estado y de la inexistente autonomía indígena en esta materia. El tema de las asociaciones de desarrollo indígena o ADIS, por sí constituyen un problema acerca de las tradicionales autoridades indígenas y sus formas de organización social las cuales son desconocidas con la imposición de las ADIS, toda vez que estas constituyen al Estado mismo introducido en la toma de decisiones indígenas mediante un artilugio legal.

Pero además de esto, el reglamento no dice nada en relación con el recurso forestal de los bosques, aspecto sobre el cual ya nos referimos líneas arriba.

\section{Conclusiones generales}

Como se ha desarrollado, los pueblos indígenas tienen derecho a gozar libremente de sus territorios y de los recursos forestales que en ellos se ubican, pero se encuentran en la obligación ciudadana de respetar los derechos de las demás personas, asumiendo las obligaciones que les son inherentes como miembros de la sociedad del país en el que viven, por ello, es factible limitar la explotación de los recursos forestales en la forma expuesta.

Esta afirmación, encuentra asidero además, en el artículo 8 del Convenio 169 de la OIT, al establecer que los pueblos indígenas tienen el derecho de mantener sus costumbres e instituciones "siempre que éstas no sean incompatibles con los derechos fundamentales definidos por el sistema jurídico nacional ni con los derechos humanos internacionalmente reconocidos".

En la misma línea, el citado numeral establece la obligación de los pueblos indígenas de asumir las obligaciones correspondientes, dentro de las cuales podemos citar el deber de proteger los bosques, los suelos, cuerpos y fuentes de agua, a fin de mantener un ambiente sano y ecológicamente equilibrado, aspectos que en todo caso forman parte de su cosmovisión.

Vale la pena acotar que las limitaciones a la explotación de sus territorios desde el recurso forestal no son antojadizas y encuentran fundamento en el derecho internacional de los derechos humanos en la expresión del derecho al medio ambiente sano, lo cual encuentra fundamento en el Protocolo a la Convención de Derechos Económicos y Sociales, así como en el Pacto Internacional de Derechos económicos, sociales y culturales, por citar dos instrumentos. 
Aunado a ello, consideramos que un argumento que plasme la posibilidad absoluta, sin limitaciones, de explotación de los recursos forestales por parte de los indígenas y en sus territorios, podría ser violatorio del derecho humano de igualdad en el tanto aquellas acciones signifiquen una afectación al medio ambiente y por lo tanto al futuro mismo de la humanidad.

Sin embargo, las limitaciones que pueden ser establecidas mediante ley deben entenderse bajo la especialidad de la ciudadanía indígena de forma tal que no implique el ejercicio del poder hegemónico del Estado, sino más bien una forma de alcanzar un equilibrio entre el respeto de derechos humanos, de manera que no se cauce una afectación al mantenimiento de la cultura indígena para que pueda ser transmitida durante generaciones.

Al entender la esencia de este tipo de limitaciones, ayudaremos a mantener un equilibro y evitar que perdamos las tradiciones indígenas y su pasado, y mejor aún que podamos conocerlas, por cuanto, en palabras de un Mayor Boruca de la comunidad de Curre (Rojas, 2006);

No es cierto que seamos un país sin tradiciones y sin pasado, la cultura del sur de nuestro país está todavía por conocerse...Ocurre que antes de la construcción de la carretera interamericana, el país prácticamente no había descubierto el sur. Con la carretera entraron al sur las corrientes modernizadoras de los años sesenta y como una ventisca helada bajada del cerro de la muerte, marchitaron las más bellas flores de la rica cultura de esa región. Hoy solo nos queda la memoria de los mayores y el sueño étnico de los pueblos indígenas en no desaparecer.

No queremos marchitar más flores, y sí queremos que la cultura indígena nos permita aprehender muchas lecciones ignoradas.

\section{Bibliografía}

Amador, J. (2003). Pensamiento étnico y pensamiento de ruptura en Curre. II Congreso sobre pueblos indígenas. San José: UCR.
De Castro Cid, B. (2003). Introducción al estudio de los Derechos Humanos. Ciudad: Editorial Universitas S.A.

Doménech, G. (2006). Derechos fundamentales y riesgos tecnológicos. Madrid: Centro de Estudios Políticos y Constitucionales.

Ferreto, A. (1985). La creación de la tierra y otras historias del buen Sibú y de los Bribris. San José: EUNED.

Ferreto, L. (2000). Costa Rica Precolombina. San José: ECR.

García, S. (2001). La Jurisprudencia de la Corte Interamericana de Derechos Humanos. México: Universidad Nacional Autónoma de México, Instituto de Investigaciones Jurídicas.

Lines, J. (1949). El arte aborigen en Costa Rica. San José: Imprenta Nacional.

Osuna, A. (2001). Teoría de los derechos humanos. Conocer para practicar. Salamanca: San Esteban-Edibesa.

Rojas, J. (2006). Así era Curre. San José: EUNED.

Stavenhagen, R. (1997). Las Organizaciones Indígenas: actores emergentes en América Latina, en Guía para los Pueblos Indígena. México: Comisión Nacional de Derechos Humanos de México.

\section{Jurisprudencia Internacional de la Corte Interamericana de Derechos Humanos}

Caso del Pueblo Saramaka vs Surinam, Sentencia del 28 de noviembre de 2007.

Caso de la Comunidad Indígena Yakye Axa VS. Paraguay, sentencia 17 de junio 2005.

Caso Comunidad Indígena Mayagna (Sumo) Awas Tingni VS. Nicaragua. Sentencia 31 de agosto 2001.

Caso Comunidad Indígena Sawhoyamaxa VS. Paraguay. Sentencia 29 de marzo 2006.

Caso Godínez Cruz VS. Honduras, Sentencia de 20 de enero de 1989.

Caso Cabrera García y Montiel Flores VS, México, sentencia de 26 de noviembre de 2010.

Caso Albán Cornejo y otros VS Ecuador, sentencia de 22 de noviembre del 2007. 
